\title{
Expression and clinical significance of SLP-2 in ovarian tumors
}

\author{
JINGJING ZHANG $^{1 *}$, XIUCAI SONG ${ }^{*}$, CUIHONG LI $^{1}$ and YANJIE TIAN ${ }^{2}$ \\ ${ }^{1}$ Department of Obstetrics and Gynecology, Yidu Central Hospital of Weifang, Weifang, Shandong 262500; \\ ${ }^{2}$ Department of Obstetrics and Gynecology, Shandong Provincial Hospital Affiliated to Shandong University, \\ Jinan, Shandong 250021, P.R. China
}

Received September 21, 2018; Accepted February 25, 2019

DOI: $10.3892 / 01.2019 .10116$

\begin{abstract}
The expression and clinical significance of stomatin-like protein 2 (SLP-2) in ovarian tumors were investigated. A total of 280 cases of ovarian tissue specimens preserved from inpatients after surgical treatments in the Department of Oncology of Yidu Central Hospital of Weifang from April 2013 to May 2016 were collected, including 130 cases of malignant ovarian tumor tissue specimens (malignant tumor group), 75 cases of benign ovarian tumor tissue specimens (benign tumor group) and 75 cases of normal ovarian tissue specimens from bilateral ovariectomy for unilateral ovarian lesions (control group). Immunohistochemistry was used to detect the expression of SLP-2 protein in the three groups. Reverse transcription-quantitative polymerase chain reaction (RT-qPCR) was utilized to detect the relative expression of SLP-2 mRNA in the three groups, and the relationship between SLP-2 and clinicopathological parameters of the ovarian cancer patients was analyzed. The patients with ovarian cancer were divided into the SLP-2 high-expression group and the SLP-2 low-expression group according to the median of SLP-2 relative expression. The survival of patients was analyzed using the Kaplan-Meier and Cox regression model. The results of immunohistochemistry showed that the positive expression rate of SLP-2 protein in the malignant tumor group was significantly higher than that in the benign tumor and control groups $(\mathrm{P}<0.001)$. The results of RT-qPCR showed that compared with the control group, the relative expression of SLP-2 mRNA in the ovarian tissues in the benign tumor group and the malignant tumor group was increased $(\mathrm{P}<0.001)$. The relative expression of SLP-2 mRNA in the malignant tumor group was higher than that in the benign tumor group $(\mathrm{P}<0.001)$. The relative expression
\end{abstract}

Correspondence to: Dr Yanjie Tian, Department of Obstetrics and Gynecology, Shandong Provincial Hospital Affiliated to Shandong University, 324 Jingwu Road, Jinan, Shandong 250021, P.R. China E-mail: jcz2h2@163.com

*Contributed equally

Key words: SLP-2, ovarian tumor, clinical stage, pathological differentiation, lymph node metastasis of SLP-2 mRNA correlated with clinical stage, pathological differentiation and lymph node metastasis of the patients with ovarian cancer $(\mathrm{P}<0.05)$. The 5-year overall survival $(\mathrm{OS})$ in the SLP-2 mRNA high expression group was significantly lower than that in the SLP-2 mRNA low expression group at 5 years $(\mathrm{P}<0.05)$. SLP-2 mRNA was an independent prognostic factor influencing OS of the patients $(\mathrm{P}<0.05)$. SLP-2 may be involved in the occurrence and development of ovarian cancer and related to the clinical stage, pathological differentiation and lymph node metastasis of the patients with ovarian cancer, which may also play a role in promoting the invasion and metastasis processes of ovarian cancer. Therefore, SLP-2 is expected to be an effective biomarker for targeted treatment and prognosis of ovarian tumor.

\section{Introduction}

Ovarian cancer is one of the most common malignant tumors of the female reproductive system, the incidence rate is only exceeded by cervical and endometrial cancer, and the mortality rate ranks first among the various gynecological malignant tumors. It is a primary operative indication of gynecological tumors (1). Ovarian cancer is characterized by insidious onset in the early stage and rapid development, and there is a lack of efficient early diagnostic methods in clinic, thus, $75 \%$ of patients are in the advanced stage when their diagnosis is confirmed (2). A significant progress has been achieved in treatment effects on ovarian cancer with the increasing standard of medical services, and surgical resection has become the major basis for ovarian cancer treatment. However, due to the easy invasion and metastasis of ovarian cancer, the 5-year survival rate of the patients is still 20-30\%; the overall survival rate remains at a low level, and the prognosis is relatively poor $(3,4)$. As a result, seeking for factors which are closely associated with the biological behavior of ovarian tumors and possess excellent repeatability and objectivity, in addition to conventional clinicopathological indexes, to screen, diagnose and treat early ovarian cancer in an effective manner is a hotspot of clinical research.

Stomatin-like protein 2 (SLP-2), an integrin of the erythrocyte membrane, is one of the stomatin gene family members, which has consistent sequences with the stomatin gene family (5). SLP-2 is located at chromosome 9q34.1 with a molecular weight of $31 \mathrm{kDa}$, and is composed of 10 exons and 9 introns. It encodes $1.5 \mathrm{~kb}$, and has typical amino acid 
Table I. Primer sequences of SLP-2 mRNA and $\beta$-actin genes.

\begin{tabular}{llc}
\hline Genes & Forward primer sequences & Reverse primer sequences \\
\hline SLP-2 & 5'-CTGGAGCCTGGTTTGAACAT-3' & 5'-AGGATCTGGGCCTGTTTCTT-3' \\
$\beta$-actin & 5'-ACACTGTGCCCATCTACGACC-3' & 5'-AGGGGCCGGACTCGTCATAGA-3' $^{\prime}$
\end{tabular}

sequences and N-terminal hydrophobic domains in structure, and can bind to the mitochondrial respiratory chain complex $(6,7)$. SLP-2 protein homologues are found to be present in both plants and vertebrates (8).

Studies have shown that SLP-2 is extremely highly expressed in multiple malignant tumors, closely related to the occurrence and development of tumors and involved in carcinogenesis (9). However, there are few reports on the expression of SLP-2 mRNA in ovarian tumors or its role in prognosis. Therefore, this study evaluated the expression of SLP-2 mRNA in ovarian cancer, investigated the roles of SLP-2 mRNA in the occurrence, development, and prognosis of ovarian cancer, and elaborated the internal relations of the gene with the development and prognosis of ovarian cancer, providing references for clinical practice.

\section{Patients and methods}

General data. A total of 280 cases of ovarian tissue specimens preserved from inpatients receiving surgical treatments in the Department of Oncology of Yidu Central Hospital of Weifang (Weifang, China) from April 2013 to May 2016 were collected. There were 130 cases of malignant ovarian tumor tissue specimens (malignant tumor group), and the patients were aged 26-65 years, with an average age of $43.46 \pm 8.31$ years. Seventyfive cases of benign ovarian tumor tissue specimens (benign tumor group) were obtained from patients aged 27-63 years, with an average age of $41.29 \pm 7.26$ years. There were 75 cases of normal ovarian tissue specimens from bilateral ovariectomy for unilateral ovarian lesions (control group), obtained from patients aged 22-56 years, with an average age of $39.16 \pm 6.47$ years. The source patients of the malignant ovarian tumor tissues were classified in accordance with the criteria of tumor-node-metastasis (TNM) staging and International Federation of Gynecology and Obstetrics (FIGO) staging of the 2014 World Health Organization (WHO) Classification of Tumors of the Female Genital Organs (10). Clinical staging: stage I $(n=8)$, stage II $(n=21)$, stage III $(n=75)$ and stage IV $(n=26)$. Pathological differentiation: well differentiated $(n=32)$, moderately differentiated $(n=46)$ and poorly differentiated $(n=52)$. There were 34 cases with lymph node metastasis and 96 cases without lymph node metastasis.

Inclusion and exclusion criteria. The inclusion criteria were as follows: i) patients who did not receive any treatment before the acquisition of ovarian tissue specimens; ii) histological sections diagnosed by chief physicians in the Department of Oncology of Yidu Central Hospital of Weifang; iii) obtained ovarian tissues stored at $-80^{\circ} \mathrm{C}$; and iv) patients with complete clinical data. This study was approved by the Ethics Committee of Yidu Central Hospital of Weifang, and all the patients and their families were informed of the study and signed the informed consent. Exclusion criteria were as follows: patients with a history and family history of mental diseases and those complicated with severe hepatic, renal or hematopoietic dysfunctions.

Immunohistochemical detection. The specimens were fixed with $10 \%$ methanol and embedded in paraffin wax to make $4 \mu \mathrm{m}$ slices. Streptavidin-biotin-peroxidase complex kit (Fuzhou Maixin Biotechnology Development Co., Ltd., Fuzhou, China) was used. The procedure was carried out by referring to the instructions. The slices were hydrated with gradient ethanol and repaired with microwave sodium citrate for $20 \mathrm{~min}$. The activity of endogenous peroxidase was blocked by peroxidase blocker. The membrane was blocked by normal animal serum. Then the mouse anti-human SLP-2 monoclonal antibody (cat. no. 60052-1-Ig; ProteinTech Group, Inc., Chicago, IL, USA) was added with a dilution of 1:200 overnight at $4^{\circ} \mathrm{C}$. The next day, biotin labelled goat anti-mouse polyclonal antibody II, (dilution, 1:700; cat. no. SA00004-1; ProteinTech Group, Inc.) streptomyces antibiotic proteinperoxidase solution and 3,3-diaminobenzidine were added to color, and then hematoxylin was used to re-stain, dehydrated and sealed with neutral gum. Referring to the scoring criteria reported by Ma et al (11), two pathologists read the film independently, and five 100-fold visual fields were taken from each slice for observation. According to the staining degree of SLP-2 positive cells and the percentage of positive cells, 0 point showed no positive cells, 1 point showed positive cells $(<10 \%), 2$ points showed positive cells $(>10 \%-<50 \%), 3$ points showed positive cells $(>50-<75 \%)$ and 4 points showed positive cells $(>75 \%)$. The criterion for positive expression of SLP2 was $>8$ points and $<8$ points were negative or low expression.

Detection via reverse transcription-quantitative polymerase chain reaction ( $R T-q P C R)$. The ovarian tissue specimens preserved at $-80^{\circ} \mathrm{C}$ were placed into liquid nitrogen, which were ground immediately and stored for use. Extraction of total RNA: TRIzol reagent (Thermo Fisher Scientific Inc., Waltham, MA, USA) was added into the specimens, shaken and left standing at room temperature for $30 \mathrm{~min}$ for adequate lysis. The operations were conducted according to the manyfacturer's instructions of the TRIzol kit. A U-T6 ultraviolet-visible spectrophotometer (Nanjing Qianzhixun Network Technology Co., Ltd., Nanjing, China) was applied to measure the absorbance of RNA, and $1 \%$ agarose gel electrophoresis was utilized to determine the purity of total RNA. The RT kit was from Thermo Fisher Scientific Inc. PCR system: $12.5 \mu 12 \mathrm{X}$ Taq PCR Master Mix, $1 \mu \mathrm{l}$ forward primers and reverse primers $(10 \mu \mathrm{mol} / \mathrm{l})$ of SLP-2 and $\beta$-actin internal reference, respectively, $2 \mu \mathrm{l}$ complementary deoxyribonucleic 
Table II. Comparison of positive expression rate of SLP-2 protein in the three groups [n (\%)].

\begin{tabular}{lccc}
\hline & & \multicolumn{2}{c}{ SLP-2 protein } \\
\cline { 3 - 4 } Groups & $\mathrm{n}$ & $\begin{array}{l}\text { Positive } \\
\text { expression }\end{array}$ & $\begin{array}{c}\text { Positive } \\
\text { rate (\%) }\end{array}$ \\
\hline Malignant tumor & 130 & 97 & 74.62 \\
Benign tumor & 75 & 24 & 32.00 \\
Control & 75 & 0 & 0.00 \\
$\chi^{2}$ & - & & 51.050 \\
P-value & - & & $<0.001$ \\
\hline
\end{tabular}

acids (cDNAs) and double-distilled $\mathrm{H}_{2} \mathrm{O}\left(\mathrm{dd}_{2} \mathrm{O}\right)$ complementing the system to $20 \mu$ l. The primer sequences are shown in Table I. All the primers were synthesized by Thermo Fisher Scientific, Inc. PCR conditions: A total of 30 cycles of predenaturation at $94^{\circ} \mathrm{C}$ for $5 \mathrm{~min}$, denaturation at $94^{\circ} \mathrm{C}$ for $45 \mathrm{sec}$, annealing at $60^{\circ} \mathrm{C}$ for $30 \mathrm{sec}$, extension at $72^{\circ} \mathrm{C}$ for $1 \mathrm{~min}$ and extension again at $72^{\circ} \mathrm{C}$ for $15 \mathrm{~min}$. The amplification data were analyzed by using the manufacturer's software, and the SLP-2 mRNA results were processed by the $2^{-\Delta \Delta C q}$ method (12). According to the median relative expression of SLP-2, ovarian cancer patients were divided into the high expression group of SLP-2 mRNA and the low expression group of SLP-2 mRNA.

Follow-up. Follow-up was conducted by telephone and other communications. According to the NCCN Guidelines (13), patients in the 1- to 2-year treatment stage were followed up every 3 months, and those in the 2- to 5-year treatment stage were followed up every 6 months. The follow-up time was 5 years, and the deadline was 31 May 2018. Total overall survival (OS) is the time from the first day of treatment to the last follow-up or death.

Statistical analysis. Statistical Product and Service Solutions (SPSS) 17.0 (Shanghai Cabit Information Technology Co., Ltd., Shanghai, China) software was applied for statistical analysis. The measurement data were presented as mean \pm standard deviation (SD), and t-test was conducted for inter-group comparisons of measurement data. Chi-square test was performed for inter-group comparisons of enumeration data, and one-way analysis of variance (ANOVA) was adopted for comparison of mean in multiple groups. Dunnett's t-test was used for pairwise comparison. Kaplan-Meier method was utilized to construct the survival curves of the patients with ovarian cancer, log-rank test for comparison, and Cox regression model was applied for multivariate analysis of prognosis. $\mathrm{P}<0.05$ indicates that the difference was statistically significant.

\section{Results}

The expression of SLP-2 protein in the ovarian tissues. The results of immunohistochemistry showed that the positive expression rate of SLP-2 protein in the malignant tumor group was $74.62 \%$ (97/130), and the positive expression rate in the benign tumor group was $32.00 \%$ (24/75), and there

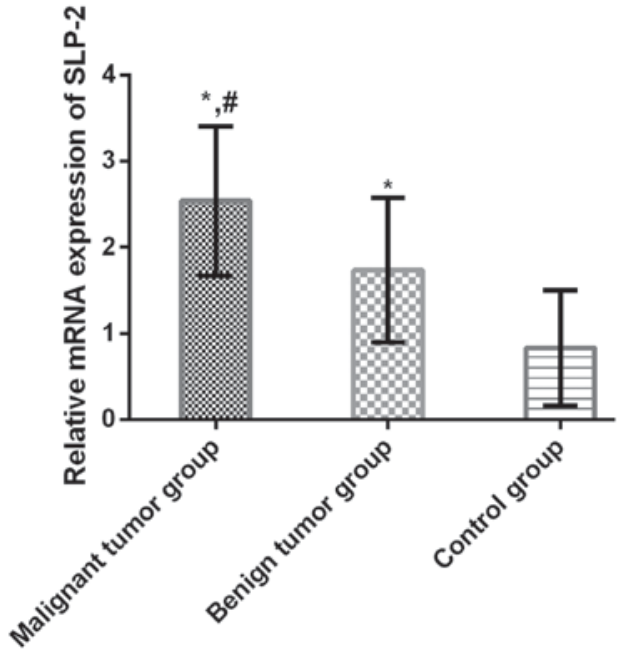

Figure 1. Comparison of relative expression of SLP-2 mRNA in three groups. The results of RT-qPCR indicate that the relative expression of SLP-2 mRNA in the benign and malignant tumor groups is increased markedly compared with that in the control group $(\mathrm{P}<0.01)$. The relative expression of SLP-2 mRNA in the malignant tumor group is significantly higher than that in benign tumor group $(\mathrm{P}<0.01)$. ${ }^{*} \mathrm{P}<0.05$ compared with that in the benign tumor group; ${ }^{\#} \mathrm{P}<0.05$ compared with that in the malignant tumor group.

was no positive expression in the control group. The positive expression rate of SLP-2 protein in the malignant tumor group was significantly higher than that in the benign tumor and control groups, and the difference was statistically significant $(\mathrm{P}<0.001)$ (Table II).

Relative expression of SLP-2 mRNA in the three groups of ovarian tissues. The relative expression of SLP-2 mRNA in the malignant tumor, the benign tumor and control groups were $2.537 \pm 0.961,1.735 \pm 0.837$ and $0.834 \pm 0.671$, respectively. Compared with that in the control group, the relative expression of SLP-2 mRNA in the benign tumor and malignant tumor groups was increased markedly $(\mathrm{P}<0.001)$. The relative expression of SLP-2 mRNA in the malignant tumor group was significantly higher than that in the benign tumor group $(\mathrm{P}<0.001)$ (Fig. 1).

Relationship of the relative expression of SLP-2 $m R N A$ in the ovarian cancer tissues with the clinicopathological parameters. We divided the ovarian cancer patients into the SLP-2 high-expression group ( $>2.537)(\mathrm{n}=70)$ and SLP-2 low-expression group $(<2.537)(\mathrm{n}=60)$ by using the median expression of SLP-2 (2.537) as the boundary value.

The results showed that the expression of SLP-2 mRNA in the ovarian cancer tissues had no correlation with the patients' age, menopause or not, preoperative tumor marker, tumor size, tumor location and depth of invasion $(\mathrm{P}>0.05)$, while it had a correlation with clinical stage, degree of pathological differentiation and lymph node metastasis $(\mathrm{P}<0.05)$. The relative expression of SLP-2 mRNA in the ovarian cancer tissues at clinical stage II-IV was remarkably higher than that at clinical stage I $(\mathrm{P}<0.001)$. Compared with that at clinical stage II, the relative expression of SLP-2 mRNA in the ovarian cancer tissues at clinical stage III-IV was notably elevated $(\mathrm{P}<0.001)$. The relative expression of SLP- 2 mRNA in the ovarian cancer tissues at clinical stage IV was obviously increased compared 
Table III. Relationship of SLP-2 mRNA expression in the ovarian cancer tissues with the clinicopathological parameters $($ mean $\pm \mathrm{SD})[\mathrm{n},(\%)]$.

\begin{tabular}{|c|c|c|c|c|c|c|c|c|}
\hline \multirow[b]{2}{*}{ Parameters } & \multirow[b]{2}{*}{$(n=130)$} & \multirow[b]{2}{*}{ SLP-2 mRNA } & \multirow[b]{2}{*}{$\mathrm{t}$} & \multirow[b]{2}{*}{ P-value } & \multicolumn{2}{|c|}{ SLP-2 mRNA } & \multirow[b]{2}{*}{$\chi^{2}$} & \multirow[b]{2}{*}{ P-value } \\
\hline & & & & & $\begin{array}{c}\text { High } \\
\text { expression } \\
(n=70)\end{array}$ & $\begin{array}{c}\text { Low } \\
\text { expression } \\
(n=60)\end{array}$ & & \\
\hline Age (years) & & & 0.828 & 0.408 & & & 2.119 & 0.146 \\
\hline$<50$ & 54 & $2.416 \pm 0.837$ & & & $25(35.71)$ & $29(48.33)$ & & \\
\hline$\geq 50$ & 76 & $2.579 \pm 1.261$ & & & $45(64.29)$ & $31(51.67)$ & & \\
\hline Menopause & & & 0.996 & 0.320 & & & 0.354 & 0.552 \\
\hline Yes & 38 & $2.617 \pm 0.832$ & & & $22(31.43)$ & $16(26.67)$ & & \\
\hline No & 92 & $2.431 \pm 1.018$ & & & $48(68.57)$ & $44(73.33)$ & & \\
\hline Preoperative tumor marker & & & 0.662 & 0.508 & & & 2.322 & 0.128 \\
\hline Positive & 97 & $2.597 \pm 0.946$ & & & $56(80.00)$ & $41(68.33)$ & & \\
\hline Negative & 33 & $2.473 \pm 0.873$ & & & $14(20.00)$ & 19 (31.67) & & \\
\hline Tumor size $(\mathrm{cm})$ & & & 1.379 & 0.170 & & & 1.536 & 0.215 \\
\hline$\leq 4$ & 77 & $2.401 \pm 0.739$ & & & $38(54.29)$ & $39(65.00)$ & & \\
\hline$>4$ & 53 & $2.631 \pm 1.162$ & & & $32(45.71)$ & $21(35.00)$ & & \\
\hline Clinical stage & & & 14.740 & $<0.001$ & & & 13.270 & 0.004 \\
\hline Stage I & 8 & $1.127 \pm 0.316$ & & & $2(2.86)$ & $6(10.00)$ & & \\
\hline Stage II & 21 & $1.693 \pm 0.627^{\mathrm{a}}$ & & & $5(7.14)$ & $16(26.67)$ & & \\
\hline Stage III & 75 & $2.237 \pm 0.894^{\mathrm{a}, \mathrm{b}}$ & & & $47(67.14)$ & $28(46.67)$ & & \\
\hline Stage IV & 26 & $3.162 \pm 1.283^{\mathrm{a}-\mathrm{c}}$ & & & $16(22.86)$ & $10(16.67)$ & & \\
\hline Pathological differentiation & & & 25.660 & $<0.001$ & & & 8.726 & 0.013 \\
\hline Well differentiated & 32 & $1.436 \pm 0.447$ & & & $10(14.29)$ & $22(36.67)$ & & \\
\hline Moderately differentiated & 46 & $2.375 \pm 0.834^{\mathrm{d}}$ & & & $28(40.00)$ & $18(30.00)$ & & \\
\hline Poorly differentiated & 52 & $3.017 \pm 1.292^{\mathrm{d}, \mathrm{e}}$ & & & $32(45.71)$ & $20(33.33)$ & & \\
\hline Lymph node metastasis & & & 3.610 & $<0.001$ & & & 5.193 & 0.023 \\
\hline Yes & 34 & $2.984 \pm 1.249$ & & & $24(34.29)$ & $10(16.67)$ & & \\
\hline No & 96 & $2.337 \pm 0.738$ & & & $46(65.71)$ & $50(83.33)$ & & \\
\hline Location & & & 1.303 & 0.195 & & & 2.383 & 1.544 \\
\hline Unilateral & 41 & $2.410 \pm 0.731$ & & & $18(25.71)$ & $23(38.33)$ & & \\
\hline Bilateral & 89 & $2.661 \pm 1.128$ & & & $52(74.29)$ & 37 (61.67) & & \\
\hline Depth of invasion $(\mathrm{cm})$ & & & 0.896 & 0.371 & & & 0.424 & 0.515 \\
\hline$<1 / 2$ & 46 & $2.618 \pm 0.834$ & & & $23(32.86)$ & $23(38.33)$ & & \\
\hline$\geq 1 / 2$ & 84 & $2.431 \pm 1.271$ & & & $47(67.14)$ & $37(61.67)$ & & \\
\hline
\end{tabular}

${ }^{\mathrm{a}} \mathrm{P}<0.001$ compared with stage I; ${ }^{\mathrm{b}} \mathrm{P}<0.001$ compared with stage II; ${ }^{\mathrm{C}}<0.001$ compared with stage III; ${ }^{\mathrm{d}} \mathrm{P}<0.001$ compared with well differentiated ones; ${ }^{\mathrm{e}} \mathrm{P}<0.001$ compared with moderately differentiated ones. SLP-2, stomatin-like protein 2.

with that at clinical stage III $(\mathrm{P}<0.001)$. The relative expression of SLP-2 mRNA displayed an increasing trend along with the advancing of ovarian cancer staging. In moderately and poorly differentiated ovarian cancer tissues, the relative expression of SLP-2 mRNA was raised $(\mathrm{P}<0.001)$, and the expression in poorly differentiated ovarian cancer tissues was significantly higher than that in moderately differentiated ones $(\mathrm{P}<0.001)$. The lower the pathological differentiation of ovarian cancer was, the higher the relative expression of SLP-2 mRNA would be. The results of RT-qPCR and western blotting indicated that the relative expression of SLP-2 mRNA in the ovarian cancer tissues with lymph node metastasis was notably higher than that without lymph node metastasis $(\mathrm{P}<0.001)$ (Table III).

Relationship between SLP-2 mRNA expression and OS. In order to identify whether SLP-2 mRNA could be taken as a prognostic biomarker for ovarian cancer, we used the Kaplan-Meier method to draw survival curves of ovarian cancer patients. The 5-year OS of patients in the SLP-2 mRNA high expression group was significantly lower than that in the SLP-2 mRNA low expression group $(\mathrm{P}<0.05)$ (Fig. 2). The Cox model analysis of the ovarian cancer patients showed 
Table IV. Univariate and multivariate Cox model analyses of OS of the patients with ovarian cancer.

\begin{tabular}{|c|c|c|c|c|}
\hline \multirow[b]{2}{*}{ Variables } & \multicolumn{2}{|c|}{ Univariate } & \multicolumn{2}{|c|}{ Multivariate } \\
\hline & $\operatorname{HR}(95 \% \mathrm{CI})$ & P-value & $\operatorname{HR}(95 \% \mathrm{CI})$ & P-value \\
\hline Age (years) & $1.431(0.483-3.264)$ & $>0.05$ & - & - \\
\hline Menopause & $1.731(0.593-7.016)$ & $>0.05$ & - & - \\
\hline Tumor size & $0.437(0.224-1.176)$ & $>0.05$ & - & - \\
\hline Clinical stage & $1.228(1.372-6.052)$ & $<0.05$ & $3.167(1.163-4.276)$ & $>0.05$ \\
\hline Pathological differentiation & $3.421(0.153-1.177)$ & $<0.05$ & $2.431(1.268-4.127)$ & $>0.05$ \\
\hline Lymph node metastasis & $3.164(1.282-11.303)$ & $<0.05$ & $2.945(1.4 .5-5.631)$ & $>0.05$ \\
\hline Depth of invasion & $2.713(1.537-3.052)$ & $>0.05$ & - & - \\
\hline SLP-2 mRNA & $2.163(0.246-4.535)$ & $<0.05$ & $0.167(0.043-0.628)$ & $<0.05$ \\
\hline
\end{tabular}

HR, hazard ratio; CI, confidence interval. SLP-2, stomatin-like protein 2.

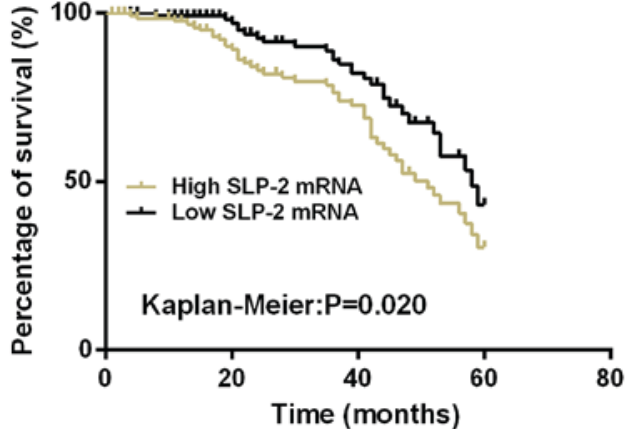

Figure 2. Relationship between SLP-2 mRNA expression and 5-year OS. The survival curves of the patients with ovarian cancer were constructed by the Kaplan-Meier method. The results manifest that the 5-year OS in the SLP-2 mRNA high expression group is significantly lower than that in the SLP-2 mRNA low expression group $(\mathrm{P}<0.05)$. SLP-2, stomatin-like protein 2.

that the relative expression of SLP-2 mRNA, clinical stage, pathological differentiation and lymph node metastasis may be prognostic factors influencing the OS of the patients with ovarian cancer $(\mathrm{P}<0.05)$. In-depth multivariate Cox model analysis demonstrated that the SLP-2 mRNA was an independent prognostic factor influencing the OS of the patients $(\mathrm{P}<0.05)$ (Table IV).

\section{Discussion}

Malignant ovarian tumor (ovarian cancer) has the largest age range of onset among the gynecologic tumors and may occur in any period of a woman's life (14). Ovarian cancer grows rapidly, with no symptoms and manifestations in the early stage. Most patients are at the advanced stage when diagnosed, in which the tumor cells have spread to a variety of organs, thereby inducing a series of complications such as rupture of tumor focus as well as hemorrhage and anemia of the body organs (15). The treatment effects of ovarian cancer are always disappointing, and the mortality rate still remains the highest among that of gynecological malignant tumors (16). Since the pathological mechanism of ovarian cancer has not been illuminated yet, research focusing on biological changes closely associated with various factors (including the occurrence, development, invasion and metastasis of the ovarian cancer) has been conducted by many scholars to clarify the specific mechanism of the disease (17). Therefore, looking for biological factors that have close correlations with the occurrence, development and prognosis of ovarian cancer cannot only provide effective screening and diagnosis for early ovarian cancer, but also accurately anticipate the detailed degree of the ovarian lesion, thus formulating an individualized and efficient therapeutic method for patients.

SLP-2 was cloned from the erythrocyte membrane by Mei et al (18), but the specific biological functions still need to be elaborated. Biological information has revealed that there are 3 translation start sites in the SLP-2 mRNA coding region, which may be involved in the tissue-specific translation (19). Studies have demonstrated that SLP-2 exists in the mature erythrocyte membrane and can conjugate with actin cytoskeleton or other integral membrane proteins. However, SLP-2 itself cannot bind to the bilayer structure of the membrane lipid, but it can act as a peripheral membrane protein, combine the stomatin proteins and other integral membrane proteins with the cytoskeletons of surrounding tissues, and participate in the tissue regulation processes of ion channel conduction as well as cholesterol-enriched lipid raft and sphingolipid. In consequence, SLP-2 becomes a leading factor for the infiltration, invasion and metastasis of malignant tumor cells by affecting the cell adhesion $(20,21)$. Research has manifested that SLP-2 is widely distributed in human tissues, with abnormally high expression in the heart, kidney and liver. It is also expressed in the brain, skeletal muscle and placenta, and SLP-2 gene and protein are highly expressed in a variety of malignant tumors (22). The results showed that the positive expression rate and the relative expression of SLP-2 protein in malignant tumor group was significantly higher than that in the benign tumor group or the control group, suggesting that the role of SLP-2 in the ovarian cancer may be concurrent with that in other malignant tumors, and that SLP-2 may be involved in the occurrence and development of ovarian cancer. The study of Huang et al (23) indicated that SLP-2 is expressed to some extent during the progression of tumor, and can mark out the micro-invasions of the tumor. It was revealed in this study that SLP-2 mRNA had a correlation with the clinical 
stage, pathological differentiation and lymph node metastasis of the tumor, and the relative expression of SLP-2 mRNA was remarkably upregulated with the exacerbation of the disease, implying that SLP-2 may have a crucial function in the invasion and metastasis processes of ovarian cancer, which may become an effective biomarker for predicting the deterioration degree of ovarian tumors. The research conducted by Deng et al (24) illustrated that the expression of SLP-2 mRNA is significantly upregulated in endometrial cancer, and closely associated with the occurrence, development, infiltration and metastasis of tumors. It is presumed that SLP-2 may function as a tumor metastasis-associated gene to further regulate the malignant behavior of the endometrial cancer. These results are similar to our study. SLP-2 may also play a role in metastasis-related genes in ovarian cancer, but the specific regulatory mechanisms need to be further studied.

The overall survival rate of ovarian cancer is not ideal, and the prognosis of the disease is still a hotspot of clinical research. In this study, the results of the constructed survival curves for patients with ovarian cancer manifested that the 5-year OS in SLP-2 mRNA high expression group declined significantly compared with that in the SLP-2 mRNA low expression group. Univariate analysis by the Cox proportional hazards regression model was performed for the patients with ovarian cancer, and the results indicated that the relative expression of SLP-2 mRNA, clinical stage, pathological differentiation and lymph node metastasis might be the prognostic factors influencing the OS of the patients with ovarian cancer. In-depth multivariate analysis via the Cox regression model demonstrated that the SLP-2 mRNA was an independent prognostic factor for OS of the patients. It was also shown that the tumor further spread when invasion and metastasis occurred in the patients. The more severe the cancer was, the poorer the prognosis was. It suggested that the SLP-2 mRNA can be considered as an indicator for judging the prognosis of ovarian cancer patients. In the study by Sun et al (25), the SLP-2 protein expression was associated with the prognosis of epithelial ovarian cancer, and the higher SLP-2 protein expression predicted worse outcome, which is similar to our study. However, that study mainly relied on the detection of the SLP-2 protein, while this study used mainly observation of the SLP-2 relative expression in ovarian cancer. Therefore, SLP-2 is expected to be a biological marker for targeted treatment and prognosis evaluation of ovarian cancer.

Immunohistochemistry and RT-qPCR were performed simultaneously to detect the relative expression of SLP-2 in the ovarian tissues in this study, which was helpful to remove the possibility of erythrocyte (SLP-2 positive cells) contamination in ovarian cancer. However, the specific mechanism of SLP-2 in the ovarian cancer tissues was not deeply investigated in this study, so there were some limitations. The occurrence, development, invasion and metastasis of tumor is a complex process controlled by multiple factors, and the interaction between the tumor cells and cytokines can accelerate proliferation and apoptosis of the tumor cells (26). SLP-2 is involved in the occurrence and development of various tumors, but its molecular biological function has not yet been clarified completely. As a result, further investigation on biological functions and characteristics is conducive to illuminate the association of SLP-2 with the occurrence, development and prognosis of malignant tumors, so as to provide a new feasible target for early diagnosis and gene therapy of malignant tumors in clinic.

In conclusion, SLP-2 may be involved in the occurrence and development of ovarian cancer and related to the clinical stage, pathological differentiation and lymph node metastasis of the patients with ovarian cancer, which may also play a role in promoting the invasion and metastasis processes of ovarian cancer. Therefore, SLP-2 is expected to be a biological marker for targeted treatment and prognosis evaluation of ovarian cancer.

\section{Acknowledgements}

Not applicable.

\section{Funding}

No funding was received.

\section{Availability of data and materials}

The datasets used and/or analyzed during the present study are available from the corresponding author on reasonable request.

\section{Authors' contributions}

JZ and XS wrote the manuscript and performed the RT-qPCR. CL collected and analyzed the basic data of patients. YT was responsible for the statistically analysis. All the authors read and approved the final manuscript.

\section{Ethics approval and consent to participate}

The study was approved by the Ethics Committee of Yidu Central Hospital of Weifang (Weifang, China). Patients who participated in this research, signed an informed consent and had complete clinical data. Signed informed consents were obtained from the patients or guardians.

\section{Patient consent for publication}

Not applicable.

\section{Competing interests}

The authors declare that they have no competing interests.

\section{References}

1. Alliance OC and Group BC: What women and their physicians need to know about the UKCTOCS study and ovarian cancer screening. Am Fam Physician 93: 903-904, 2016.

2. Shi Q, Wang XS, Li G, Shah ND, Orlowski RZ, Williams LA, Mendoza TR and Cleeland CS: Racial/ethnic disparities in inflammatory gene single-nucleotide polymorphisms as predictors of a high risk for symptom burden in patients with multiple myeloma 1 year after diagnosis. Cancer 121: 1138-1146, 2015.

3. Ferrara N: Microvascular density as a predictive biomarker for bevacizumab survival benefit in ovarian cancer: Back to first principles? J Natl Cancer Inst 109: 109, 2017.

4. Kommoss S, Winterhoff B, Oberg AL, Konecny GE, Wang C, Riska SM, Fan JB, Maurer MJ, April C, Shridhar V, et al: Bevacizumab may differentially improve ovarian cancer outcome in patients with proliferative and mesenchymal molecular subtypes. Clin Cancer Res 23: 3794-3801, 2017. 
5. Mitsopoulos P, Lapohos O, Weraarpachai W, Antonicka H, Chang YH and Madrenas J: Stomatin-like protein 2 deficiency results in impaired mitochondrial translation. PLoS One 12: e0179967, 2017.

6. Conrad KA, Rodriguez R, Salcedo EC and Rauceo JM: The Candida albicans stress response gene stomatin-like protein 3 is implicated in ROS-induced apoptotic-like death of yeast phase cells. PLoS One 13: e0192250, 2018.

7. Feng Q, Hu ZY, Liu XQ, Zhang X, Lan X, Geng YQ, Chen XM, He JL, Wang YX and Ding YB: Stomatin-like protein 2 is involved in endometrial stromal cell proliferation and differentiation during decidualization in mice and humans. Reprod Biomed Online 34: 191-202, 2017.

8. Yang X, Zang W, Xuan X, Wang Z, Liu Z, Wang J, Cui J and Zhao G: [Corrigendum] miRNA-1207-5p is associated with cancer progression by targeting stomatin-like protein 2 in esophageal carcinoma. Int J Oncol 52: 1363, 2018.

9. Küçük I,Tanoğlu A,Öncü K, Yılmazİ,KaraM,Beyazıt Y, AkyolT, Kaplan M, Özarı HO and Yazgan Y: Immunohistochemical activity of prohibitin-2 and stomatin-like protein-2 in patients with ulcerative colitis. Turk J Gastroenterol 27: 233-238, 2016.

10. Hauptmann S, Friedrich K, Redline R and Avril S: Ovarian borderline tumors in the 2014 WHO classification: Evolving concepts and diagnostic criteria. Virchows Arch 470: 125-142, 2017.

11. Ma W, Xu Z, Wang Y, Li W, Wei Z, Chen T, Mou T, Cheng M, Luo J, Luo T, et al: A Positive feedback loop of SLP2 activates MAPK signaling pathway to promote gastric cancer progression. Theranostics 8: 5744-5757, 2018

12. Livak KJ and Schmittgen TD: Analysis of relative gene expression data using real time quantitative PCR and the 2(-Delta Delta C(T)) method. Methods 25: 402 408, 2001.

13. Morgan RJ Jr, Armstrong DK, Alvarez RD, Bakkum-Gamez JN, Behbakht K, Chen LM, Copeland L, Crispens MA, DeRosa M, Dorigo O, et al: Ovarian cancer, version 1.2016, NCCN clinical practice guidelines in oncology. J Natl Compr Canc Netw 14: $1134-1163,2016$

14. Horikawa N, Abiko K, Matsumura N, Hamanishi J, Baba T, Yamaguchi K, Yoshioka Y, Koshiyama M and Konishi I: Expression of vascular endothelial growth factor in ovarian cancer inhibits tumor immunity through the accumulation of myeloid-derived suppressor cells. Clin Cancer Res 23: 587-599, 2017.

15. Park JY, Kim DY, Suh DS, Kim JH, Kim YM, Kim YT and Nam JH: Analysis of outcomes and prognostic factors after fertility-sparing surgery in malignant ovarian germ cell tumors. Gynecol Oncol 145: 513-518, 2017.
16. Lutgendorf SK, Thaker PH, Arevalo JM, Goodheart MJ, Slavich GM, Sood AK and Cole SW: Biobehavioral modulation of the exosome transcriptome in ovarian carcinoma. Cancer 124: 580-586, 2018.

17. Chapel DB, Husain AN, Krausz T and McGregor SM: PAX8 expression in a subset of malignant peritoneal mesotheliomas and benign mesothelium has diagnostic implications in the differential diagnosis of ovarian serous carcinoma. Am J Surg Pathol 41: 1675-1682, 2017.

18. Mei Y, Yao F, Wu Y, Chu B, Cheng C, Liu Y, Li X, Zou X and Hou L: Identification and expression of the elongator protein 2 (Ajelp2) gene, a novel regeneration-related gene from the sea cucumber Apostichopus japonicus. Mol Biol Rep 41: 4985-4996, 2014.

19. Zhang L and Liu FJ: Expression of SLP-2 gene and CCBE1 are associated with prognosis of rectal cancer. Eur Rev Med Pharmacol Sci 21: 1214-1218, 2017.

20. Chi $\mathrm{H}$ and $\mathrm{Hu} \mathrm{YH}$ : Stomatin-like protein 2 of turbot Scopthalmus maximus: Gene cloning, expression profiling and immunoregulatory properties. Fish Shellfish Immunol 49: 436-441, 2016.

21. Bartolome A, Boskovic S, Paunovic I, Bozic V and Cvejic D: Stomatin-like protein 2 overexpression in papillary thyroid carcinoma is significantly associated with high-risk clinicopathological parameters and BRAFV600E mutation. APMIS 124: 271-277, 2016.

22. Wai T and Langer T: Mitochondrial dynamics and metabolic regulation. Trends Endocrinol Metab 27: 105-117, 2016.

23. Huang Y, Chen Y, Lin X, Lin Q, Han M and Guo G: Clinical significance of SLP-2 in hepatocellular carcinoma tissues and its regulation in cancer cell proliferation, migration, and EMT. OncoTargets Ther 10: 4665-4673, 2017.

24. Deng H, Deng Y, Liu F, Chen J, Li Z, Zhao K, Guan X and Liang W: Stomatin-like protein 2 is overexpressed in cervical cancer and involved in tumor cell apoptosis. Oncol Lett 14: 6355-6364, 2017.

25. Sun F, Ding W, He JH, Wang XJ, Ma ZB and Li YF: Stomatin-like protein 2 is overexpressed in epithelial ovarian cancer and predicts poor patient survival. BMC Cancer 15: 746, 2015.

26. Ardolino $\mathrm{M}$ and Raulet DH: Cytokine therapy restores antitumor responses of NK cells rendered anergic in MHC I-deficient tumors. OncoImmunology 5: e1002725, 2015.

This work is licensed under a Creative Commons Attribution-NonCommercial-NoDerivatives 4.0 International (CC BY-NC-ND 4.0) License. 